\title{
Neurofibromatosis type 3
}

INSERM

\section{Source}

INSERM. (1999). Orphanet: an online rare disease and orphan drug data base.

Neurofibromatosis type 3. ORPHA:93921

Neurofibromatosis (NF) type 3 (NF3), also known as schwannomatosis, is the least frequent form of the rare genetic disorder neurofibromatosis. It is clinically and genetically distinct from NF1 and NF2 and is characterized by the development of multiple schwannomas (nerve sheath tumors), without involvement of the vestibular nerves. NF3 develops in adulthood and is often associated with chronic pain. Dysesthesia and paresthesia may also be present. Common localizations include the spine, peripheral nerves, and the cranium. 